Article

\title{
UPLC-QTOF-MS Identification of the Chemical Constituents in Rat Plasma and Urine after Oral Administration of Rubia cordifolia L. Extract
}

\author{
Zuoliang Zheng ${ }^{1,2,3,+}$, Shengqing Li ${ }^{3,+}$, Yuping Zhong ${ }^{3}$, Ruoting Zhan ${ }^{1,2}$, Yan Yan ${ }^{3}$, \\ Huafeng Pan ${ }^{4, *}$ and Ping Yan ${ }^{1,2, *}$ \\ 1 Research Center of Chinese Herbal Resource Science and Engineering, Guangzhou University of Traditional \\ Chinese Medicine, Guangzhou 510006, China; 15975502279@sina.cn (Z.Z.); ruotingzhan@vip.163.com (R.Z.) \\ 2 Key Laboratory of Chinese Medicinal Resources from Lingnan of Ministry of Education, Joint Laboratory of \\ National Engineering Research Center for the Pharmaceutics of Traditional Chinese Medicines, \\ Guangzhou University of Traditional Chinese Medicine, Guangzhou 510006, China \\ 3 Institute of Traditional Chinese Medicine, Guangzhou University of Traditional Chinese Medicine, \\ Guangzhou 510006, China; gzzyylsq@sina.com (S.L.); 15914272434@sina.cn (Y.Z.); \\ gzzyydxyy@sina.com (Y.Y.) \\ 4 Guangzhou University of Traditional Chinese Medicine, Guangzhou 510006, China \\ * Correspondence: gzphf@126.com (H.P.); ycyyp22@hotmail.com (P.Y.); Tel.: +86-20-3658-8339 (H.P.); \\ +86-020-3422-1225 (P.Y.) \\ + These authors contributed equally to this work.
}

Received: 30 June 2017; Accepted: 5 August 2017; Published: 11 August 2017

\begin{abstract}
An effective ultra-performance liquid chromatography coupled with the quadrupole time-of-flight tandem mass spectrometry (UPLC/Q-TOF/MS) method was developed for analysing the chemical constituents in rat plasma and urine after the oral administration of Rubia cordifolia L. extract. Under the optimized conditions, nine of 11 prototypes in rat plasma and four prototypes in urine were identified or characterized by comparing the retention time, accurate mass, fragmentation patterns, reference compounds, and literature data. In total, six metabolites, including alizarin-1-O- $\beta$-glucuronide, alizarin-2-O- $\beta$-glucuronide, alizarin-1-O-sulfation, alizarin-2-O-sulfation, purpurin-1-O- $\beta$-glucuronide, and purpurin-3-O- $\beta$-glucuronide, were identified in rat plasma, which were confirmed by lavaging standard solutions. Purpurin was found to be able to be transformed into alizarin based on the results in which alizarin was detected in rat plasma after the oral administration of a purpurin solution. In total, four metabolites were found in rat urine, but their chemical structures were not confirmed. The results indicate that the metabolic pathway of alizarin involves glucuronidation and sulfation, with the purpurins having undergone glucuronidation. The components absorbed into the blood, and the metabolites have the opportunity to become bioactive constituents. The experimental results would supply a helpful chemical basis for further research on the mechanism of actions of Rubia cordifolia $\mathrm{L}$.
\end{abstract}

Keywords: Rubia cordifolia L.; UPLC/Q-TOF-MS; metabolites; alizarin; purpurin

\section{Introduction}

Rubia cordifolia L. was officially listed in the 2015 edition of the Chinese Pharmacopoeia and is widely used as a traditional Chinese medicine for the treatment of tuberculosis, contusions, menoxenia, and rheumatism in China, Japan, Korea, and India [1]. Many constituents, including anthraquinones, naphthoquinones, naphthodroquinones, triterpenes [2,3], and iridoids [4,5] were isolated and identified from the genus Rubia. To the best of our knowledge, different parts of Rubia cordifolia L. have different chemical compositions. However, ony the bioactive components that are detected in the 
blood could exert therapeutic effects and contribute to the quality of traditional Chinese herbal medicines (TCMs) [6]. In the previous literature, several anthraquinones and anthraquinone derivatives were proven to exert different pharmacological activities [7], including antifungal, antioxidant, antimicrobial, anti-inflammation, antibacterial, and anticancer activities [8-12]. Purpurin showed stronger antioxidant and better enzyme inhibitory effects than mollugin [13], which had a good reputation for its anti-carcinogenic and anti-viral activities [14]. In addition, pseudopurpurin could increase the bone mineral density and enhance the geometry of its architecture [15]. Rubiadin exhibits a potent hepatoprotective action against carbon tetrachloride-induced hepatic damage in rats [16].

The research on drug bioactivities is based on the drug metabolism. Therefore, the identification of drug prototypes and metabolites in vitro or in vivo is of vital importance for elucidating drug pharmacological mechanisms and pharmacokinetic behavior. Anthraquinones and anthraquinone derivatives have been proved to be the main active substance in Rubia cordifolia L. acting in disease. However, its prototypes and metabolites in vivo have not been reported. Nowadays, it is difficult to identify them due to interference from endogenous metabolites, their extremely low concentrations [17], a lack of standards, and diverse structure types. Their many isomers further increased the difficulty of the analysis and the uncertainty of the results. Therefore, the ultra-performance liquid chromatography coupled with the quadrupole time-of-flight tandem mass spectrometry (UPLC/Q-TOF-MS) has been proved to be an effective analytical tool for the determination of chemical constituents and metabolites in biological samples by means of its selectivity, sensitivity, and speediness [18-20]. In this paper, a UPLC/Q-TOF-MS method was developed to systematically analyze the prototypes and metabolites in rat plasma and urine after oral administration of Rubia cordifolia L. for revealing the metabolic pathways and understanding the mechanism of action of Rubia cordifolia $\mathrm{L}$.

\section{Results and Discussion}

\subsection{Identification of Chemical Components in Rubia cordifolia L. Extract}

The identification of the chemical constituents in the plasma and urine was based on the analysis of the components of the Rubia cordifolia L. extract. The information from the 40 compounds in Rubia cordifolia L. extract, including the chromatogram and $\mathrm{MS}^{2}$ spectra, was recorded (Table 1). Compounds 23, 25, 26, 31, and 32 were confirmed to be 6-hydroxyrubiadin, alizarin, purpurin, physcion and rubiadin, respectively, by comparison with the reference compounds. A total of nine compounds were tentatively characterized based on the comparison of literature data and the analysis of the fragmentation regularities using the PeakView (Version 2.0, AB SCIEX) [15,21,22]. The remaining 26 ingredients were not further analyzed due to the lack of authentic compounds and reference data. The profiling of these compounds was shown by a total ion chromatogram (TIC) in Figure 1.

Table 1. Compounds identified in Rubia cordifolia L. extract.

\begin{tabular}{llllll}
\hline NO. & $\begin{array}{l}\text { RT } \\
(\mathbf{m i n})\end{array}$ & Mass Found & $\begin{array}{l}\text { Error } \\
(\mathbf{p p m})\end{array}$ & MS $^{\mathbf{2}}$ Ions & Identification \\
\hline $\mathbf{1}$ & 10.68 & 461.0732 & 1.2 & $417,298,280,255,226$ & \\
$\mathbf{2}$ & 12.55 & 610.4194 & 0.1 & $564,546,451,338,225,130$ & \\
$\mathbf{3}$ & 13.7 & 723.5057 & 0 & $677,659,564,451,338,225$ & \\
$\mathbf{4}$ & 14.52 & 836.5906 & 0.3 & 790,225 & \\
$\mathbf{5}$ & 15.15 & 949.6771 & 0.2 & 903 & Ruberythric acid \\
$\mathbf{6}$ & 17.62 & 563.1419 & 0.2 & 269,240 & \\
$\mathbf{7}$ & 17.86 & 577.1579 & 0.2 & $577,269,240$ & 2-Methyl-1,3,6-hydroxy- \\
$\mathbf{8}$ & 19.57 & 619.1667 & 0.9 & $577,559,269,240$ & 9,10-anthraquinone-3-O- \\
& & & & & 3-D-glucopyranoside \\
$\mathbf{9}$ & 20.06 & 417.0836 & 1.5 & 255,241 & Pseudopurpurin \\
\hline $\mathbf{1 0}$ & 21.32 & 299.0201 & 0.6 & $255,227,183,171,143,129$ & \\
\hline
\end{tabular}


Table 1. Cont.

\begin{tabular}{|c|c|c|c|c|c|}
\hline NO. & $\begin{array}{l}\text { RT } \\
(\mathrm{min})\end{array}$ & Mass Found & $\begin{array}{l}\text { Error } \\
(\mathrm{ppm})\end{array}$ & MS $^{2}$ Ions & Identification \\
\hline 11 & 21.41 & 239.0346 & 1.1 & $211,195,183,167,155$ & An isomer of alizarin \\
\hline 12 & 21.43 & 283.0254 & 0.4 & $239,211,195,167$ & Munjistin \\
\hline 13 & 21.59 & 619.1683 & 0 & $577,269,240$ & \\
\hline 14 & 21.61 & 665.1745 & 0.1 & $619,577,372,269,239$ & \\
\hline 15 & 23.05 & 267.0304 & 0.6 & 223,195 & Nordamnacanthal \\
\hline 16 & 23.1 & 473.1093 & 0.6 & 268,240 & \\
\hline 17 & 23.12 & 345.0408 & 0.5 & $317,301,289,273,260,245$ & Unknown \\
\hline 18 & 23.93 & 661.1793 & 0.4 & $619,601,269,240$ & \\
\hline 19 & 24.4 & 401.0887 & 0.3 & $356,328,300,272,244$ & Alizarin-2-O-Glc \\
\hline 20 & 25.37 & 801.3497 & 0.1 & $755,630,556,493,460$ & \\
\hline 21 & 26.23 & 253.0504 & 0.1 & $225,209,195$ & An isomer of rubiadin \\
\hline 22 & 28.42 & 453.0623 & 0 & $409,394,350,306,293$ & \\
\hline 23 & 29.53 & 269.0461 & 0.5 & $254,241,223,210,195$ & 6-Hydroxyrubiadin \\
\hline 24 & 28.45 & 317.1033 & 0 & $213,185,157,129$ & \\
\hline 25 & 30.56 & 239.0343 & 0.6 & $211,195,167,155$ & Alizarin \\
\hline 26 & 30.9 & 255.0297 & 0 & $227,183,171,143,129,101$ & Purpurin \\
\hline 27 & 30.91 & 293.1764 & 0.1 & $236,221,205,192,177$ & \\
\hline 28 & 30.99 & 593.1315 & 0.3 & $549,505,417,383,357,313$ & \\
\hline 29 & 31.15 & 745.2326 & 0.1 & $644,513,496,482$ & \\
\hline 30 & 31.63 & 297.1531 & 1 & $\begin{array}{l}269,254,239,223,211,197 \\
183,169\end{array}$ & $\begin{array}{l}\text { 1-Hydroxy-2-carboxyl- } \\
\text { 3-methoxy-anthraquinone }\end{array}$ \\
\hline 31 & 33.74 & 283.0612 & 2.3 & $268,240,211$ & Physcion \\
\hline 32 & 34.32 & 253.0502 & 0.5 & $225,209,195$ & Rubiadin \\
\hline 33 & 34.77 & 297.0773 & 0.5 & $251,223,195$ & \\
\hline 34 & 34.93 & 457.0722 & 0.4 & $413,384,369,356$ & \\
\hline 35 & 36.28 & 441.135 & 0.1 & $372,313,297,269$ & \\
\hline 36 & 36.42 & 313.0511 & 0.1 & $285,269,257,229,201$ & \\
\hline 37 & 37.7 & 325.1845 & 0.7 & $279,197,183,119$ & \\
\hline 38 & 38.36 & 295.228 & 1 & $277,259,183,171$ & \\
\hline 39 & 38.52 & 339.2003 & 0.3 & $197,183,119$ & \\
\hline 40 & 43.24 & 353.2123 & 0 & 177,163 & \\
\hline
\end{tabular}

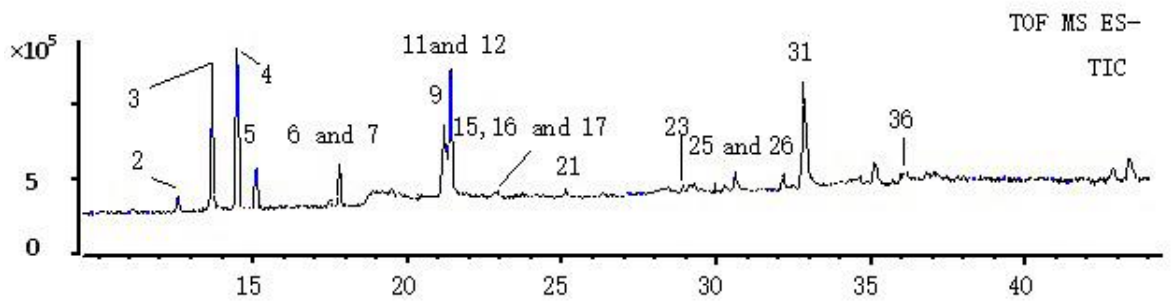

Figure 1. TIC of Rubia cordifolia L. extract.

Compound 10 (Table 1) presented the parent ion at a $m / z$ of $299.0201\left([\mathrm{M}-\mathrm{H}]^{-}, 0.6 \mathrm{ppm}\right)$. The product ions at the $\mathrm{m} / z$ of 255 contributed to the elimination of $\mathrm{CO}_{2}$. The fragment ions $(227,183$, 171,143 , and 129) that were observed in the MS² spectra (Figure 2) were in accord with the purpurins (compound 26; Figure 2). Thus, the compound $\mathbf{1 0}$ was identified as pseudopurpurin. 

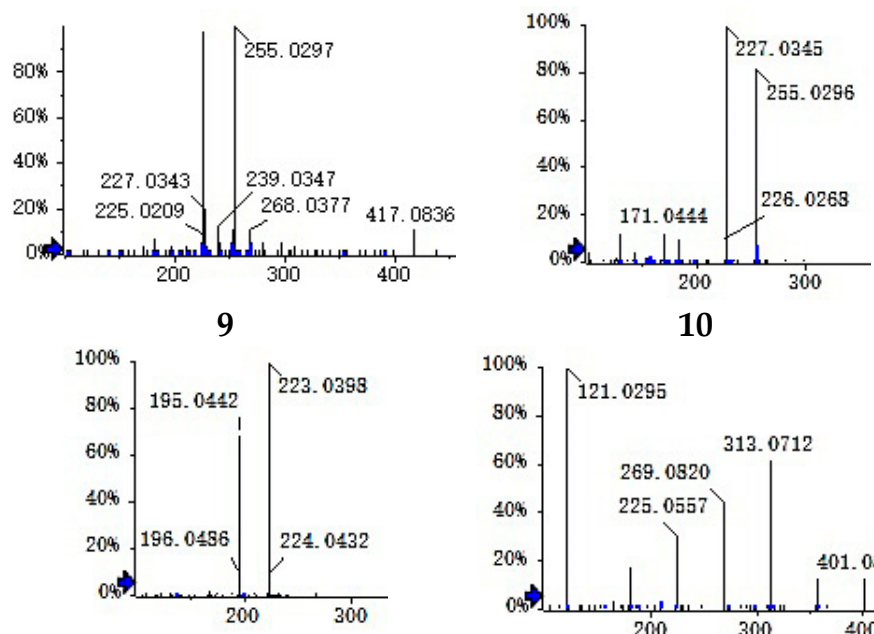

15

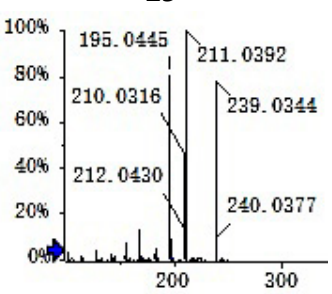

11 (an isomer of alizarin)

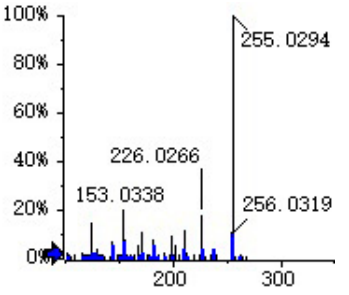

6 (an isomer of purpurin)

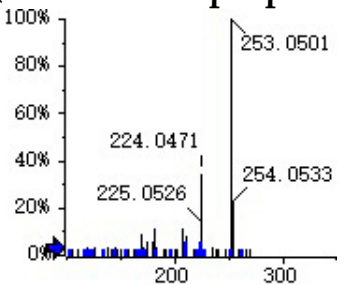

21 (an isomer of rubiadin)

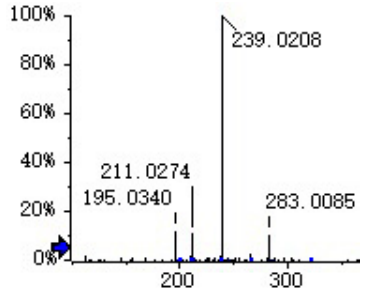

2 (Table 2)

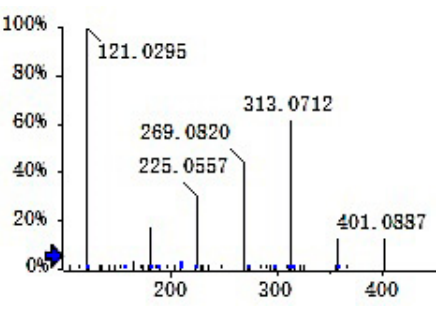

19

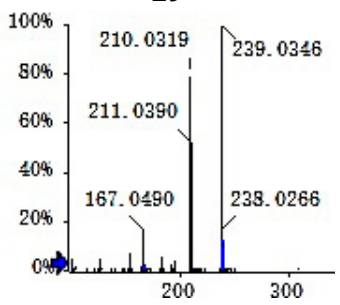

25 (alizarin)

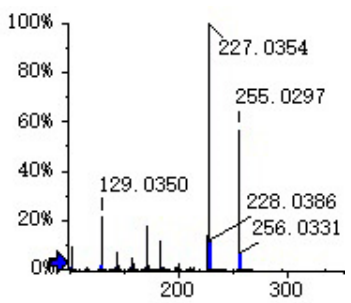

26 (purpurin)

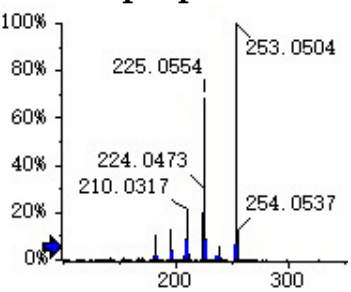

32 (rubiadin)

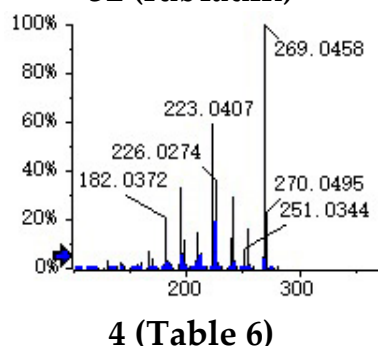

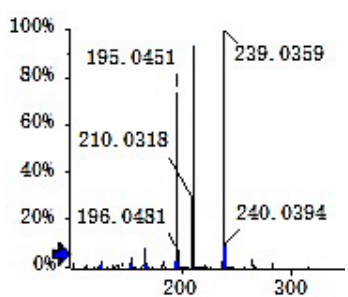

12

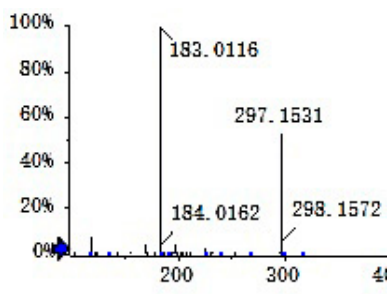

30

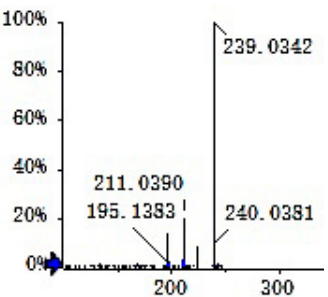

Alizarin standard

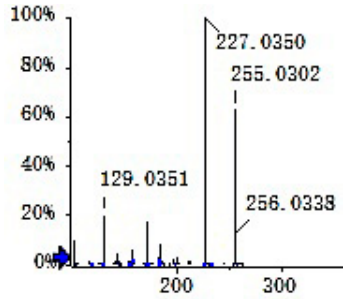

Purpurin standard

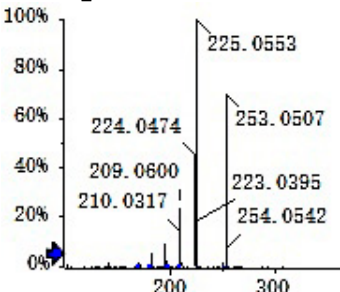

Rubiadin standard

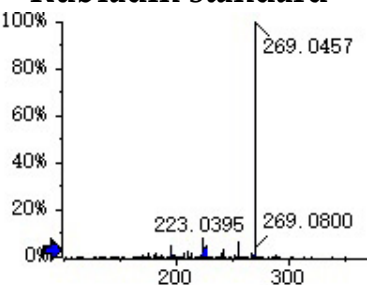

1 (Table 6)

Figure 2. Spectra of compounds. 
Compounds 11 and 25 at retention times of 21.41 and 30.56 min shared the same precursor ion at the $m / z$ of 239.0346 and recorded the coincident fragmentation pathways. Therefore, they were considered isomers. Compound $\mathbf{2 5}$ had been determined as alizarin (Figure 2). Thus, the compounds 6 (Table 2) and $\mathbf{2 1}$ were tentatively identified as isomers of purpurin and rubiadin, respectively.

Table 2. Compounds identified in rat plasma after oral administration of Rubia cordifolia L. extract.

\begin{tabular}{llllll}
\hline NO. & RT (min) & Mass Found & Error $(\mathbf{p p m})$ & MS $^{\mathbf{2}}$ Ions & Identification \\
\hline $\mathbf{1}$ & 11.8 & 497.3337 & 0 & $451,433,225$ & \\
$\mathbf{2}$ & 15.34 & 459.0562 & 0.2 & $283,239,211,195$ & Glucuronide of munjistin \\
$\mathbf{3}$ & 19.64 & 431.0611 & 0.6 & $255,227,183$ & Purpurin-1-O- $\beta$-glucuronide \\
$\mathbf{4}$ & 20.04 & 415.0670 & 0.3 & $239,211,167$ & Alizarin-1-O- $\beta$-glucuronide \\
$\mathbf{5}$ & 20.09 & 415.0672 & 0.2 & $239,211,167$ & Alizarin-2-O- $\beta$-glucuronide \\
$\mathbf{6}$ & 20.09 & 255.0298 & 0.1 & $255,227,183,171$ & An isomer of purpurin \\
$\mathbf{7}$ & 20.28 & 431.0613 & 1.2 & 255,227 & Purpurin-3-O- $\beta$-glucuronide \\
$\mathbf{8}$ & 20.79 & 318.9917 & 0.4 & $239,211,183,167,155$ & Alizarin-1-O-sulfation \\
$\mathbf{9}$ & 21.32 & 299.0201 & 0.6 & $255,227,183,171,143$ & Pseudopurpurin \\
$\mathbf{1 0}$ & 21.41 & 239.0346 & 1.1 & $211,195,183,167,155$ & An isomer of alizarin \\
$\mathbf{1 1}$ & 21.43 & 283.0254 & 0.4 & $239,211,195,167$ & Munjistin \\
$\mathbf{1 2}$ & 22.6 & 667.1307 & 0.2 & 491,315 & Glucuronide of compound \\
$\mathbf{1 3}$ & 22.89 & 318.9917 & 0.3 & $239,211,183,167,155$ & Alizarin-2-O-sulfation \\
$\mathbf{1 4}$ & 23.05 & 267.0304 & 0.6 & 223,195 & Nordamnacanthal \\
$\mathbf{1 5}$ & 23.12 & 345.0408 & 0.5 & $317,301,289,273,260$ & \\
$\mathbf{1 6}$ & 24.4 & 401.0879 & 0.3 & $356,328,300,272,244$ & Alizarin-2-O-Glc \\
$\mathbf{1 7}$ & 26.23 & 253.0504 & 0.1 & $225,209,195$ & An isomer of rubiadin \\
$\mathbf{1 8}$ & 30.56 & 239.0343 & 0.6 & $211,195,167,155$ & Alizarin \\
$\mathbf{1 9}$ & 30.9 & 255.0297 & 0 & $227,183,171,143,129$ & Purpurin \\
$\mathbf{2 0}$ & 30.91 & 293.1764 & 0.1 & $236,221,205,192,177$ & Rubiadin \\
$\mathbf{2 1}$ & 34.32 & 253.0502 & 0.5 & $225,209,195$ & \\
\hline
\end{tabular}

Based on the molecular weight, fragmentation ions, and previously published data [21], the compounds $\mathbf{9}, \mathbf{1 2}, \mathbf{1 5}, \mathbf{1 9}$, and $\mathbf{3 0}$ were tentatively confirmed as 2-methyl-1,3,6-hydroxy-9,10anthraquinone-3-O- $\beta$-D-glucopyranoside, munjistin, nordamnacanthal, alizarin-2-O-Glc, and 1-hydroxy-2-carboxyl-3-methoxy-anthraquinone, respectively. The $\mathrm{MS}^{2}$ spectra of compounds $\mathbf{9}$, 11, 12, 15, 19, 21, 25, and 32 are presented in Figure 2.

\subsection{Detection of the Prototype Components and Metabolites in Rat Plasma}

After eliminating the interference of endogenous substances, 21 compounds (including 11 prototype components and 10 metabolites) were found, but only 13 of these components were tentatively identified (Figure 3).

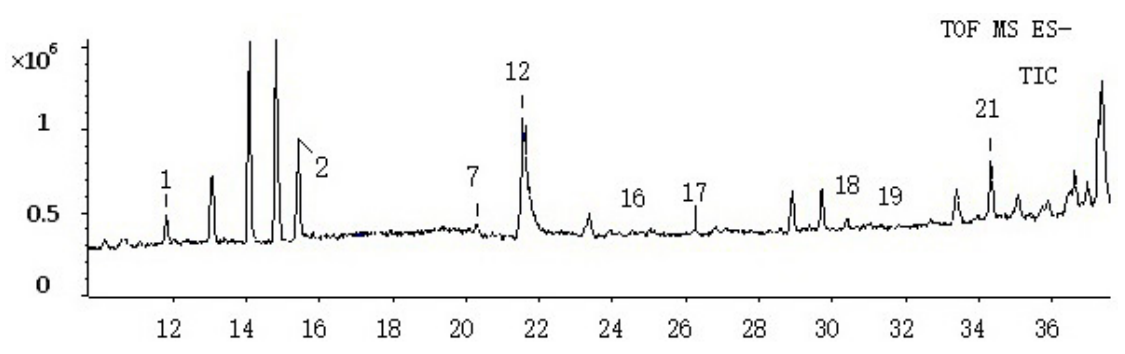

Figure 3. Cont. 


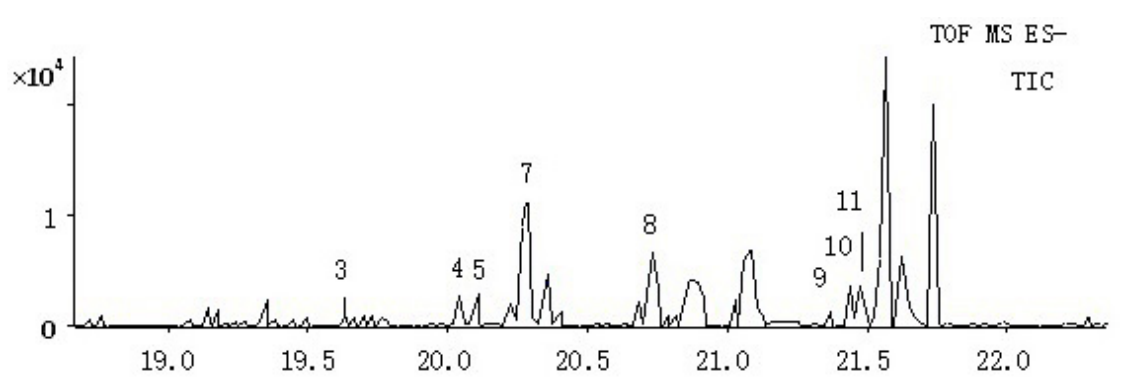

Figure 3. TIC of the rat plasma sample.

As shown in Tables 1 and 2, the compounds 10, 11, 12, 15, 17, 19, 21, 25, 26, 27, and 32 in the Rubia cordifolia L. extract correspond to the compounds 9, 10, 11, 14, 15, 16, 17, 18, 19, 20, and 21 in the rat plasma, respectively. It was concluded that these compounds can be regarded as prototype components.

According to Table 2, compound 2 shows a parent ion at a $m / z$ of 459.0562 and product ions at the $m / z$ of $283,239,211$, and 195. The product ion at a $m / z$ of 283 was 176 Da less than the deprotonated molecule. Based on the chemical constituents of Rubia cordifolia L., the fragment at the $m / z$ of 283 represents the structure of munjistin. Thus, it was concluded that compound 2 was generated through the glucuronide conjugation of munjistin. Therefore, compounds $\mathbf{4}$ and $\mathbf{5}$ were identified as glucuronide conjugations of alizarin, while compounds 3 and $\mathbf{7}$ were confirmed to be the glucuronide conjugation of purpurin. The $\mathrm{MS}^{2}$ spectrum of compound 2 is shown in Figure 2. The parent ions of compounds $\mathbf{8}$ and $\mathbf{1 3}$ at the $\mathrm{m} / z$ of 319 are $80 \mathrm{Da}$ larger than alizarin. Thus, they were identified as sulfation products of alizarin.

The metabolites of alizarin and purpurin metabolites were observed in rat plasma after the administration of an alizarin solution and a purpurin solution, respectively. Figures 4 and 5 obtained using Metabolite Pilot 1.5 software show the metabolite chromatograms of alizarin and purpurin, respectively. The information for the metabolites are shown in Tables 3 and 4. M1 and M3 were identified as alizarin-1-O- $\beta$-glucuronide and alizarin-2-O- $\beta$-glucuronide, based on their same molecular weight, different retention times, and different peak areas (the peak area of M3 $>$ M1), because the $\beta-O H$ of antraquinones is more active and the result is consistent with the study of emodin [23]. Therefore, M2 and M4 were similarly confirmed to be alizarin-1-O-sulfation and alizarin-2-O-sulfation, respectively. According to the Table 4 and the $\mathrm{MS}^{2}$ spectra (shown in Figure 5), M1 and M2 in the metabolite chromatogram of purpurin were identified as purpurin-1-O- $\beta$-glucuronide and purpurin-3-O- $\beta$-glucuronide, respectively, while $\mathrm{M} 4$ was regarded as alizarin. The interference of alizarin in purpurin standard can be excluded due to the purity of purpurin standard and the peak area of alizarin (shown in Table 4). The MS² spectrum of M4 can be found in Figure 5. Therefore, it is concluded that purpurin could transform into alizarin in the rat body. The result is consistent with the study of emodin that stated that emodin could transform into chrysophanol [24]. The M3 was not determined, but it was deduced to be a metabolite of M2 due to their same fragment ions at the $m / z$ of 431,255 , and 227. The metabolic pathways of alizarin and purpurin are shown in Figures 6 and 7, respectively. The chemical structures of the metabolites and the identified compounds are summarized in Table 5. The glucuronic acid (GlcA) and sulfuric acid ester group binding sites in the anthraquinones are $\alpha-\mathrm{OH}$ and $\beta-\mathrm{OH}$. As shown in Table 2, the compounds $\mathbf{1}, \mathbf{2}, \mathbf{6}$, and $\mathbf{1 2}$ were found as metabolites. However, further studies are needed to reveal the structures of these compounds. 


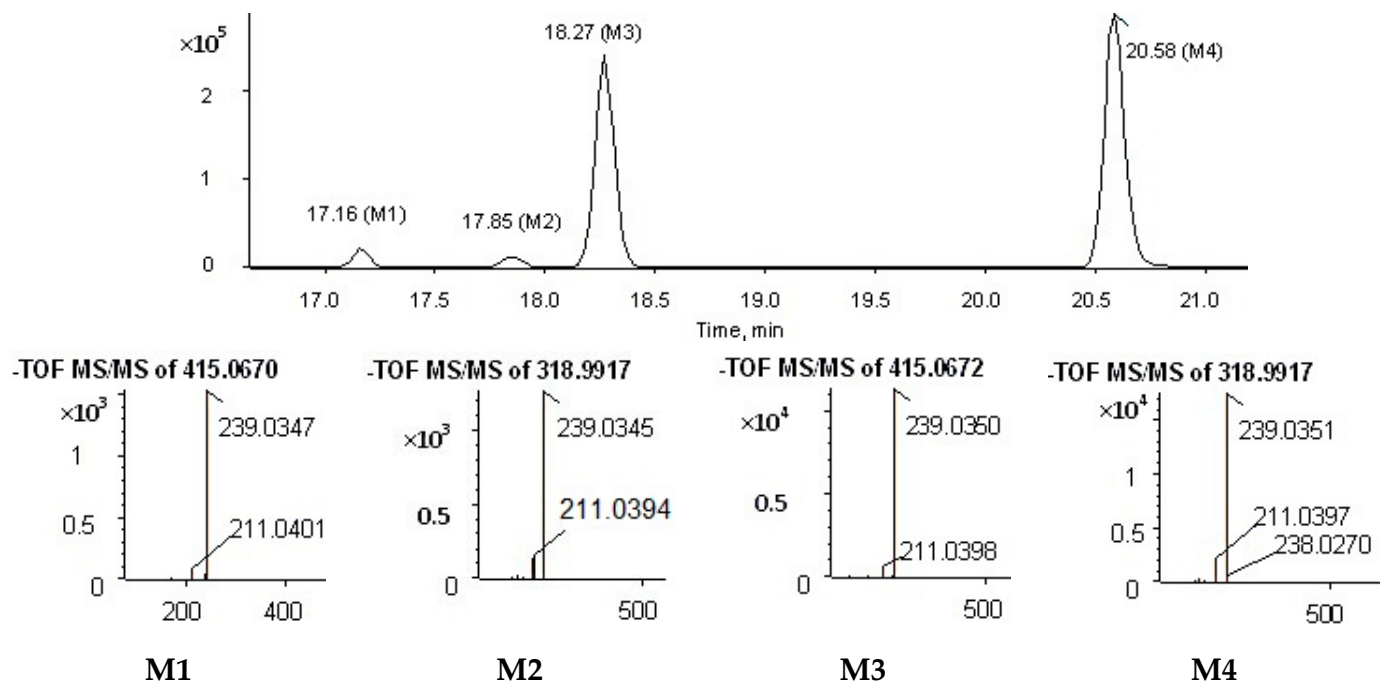

Figure 4. Metabolite chromatogram of alizarin.

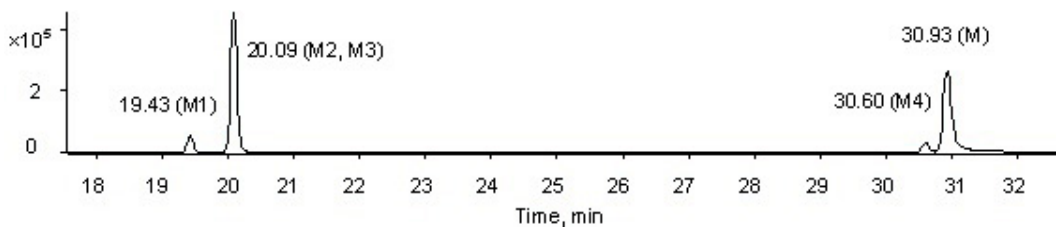

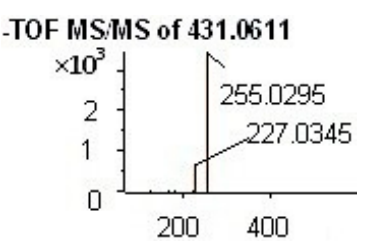

M1

\section{-TOF IMSIMIS of 431.0613}

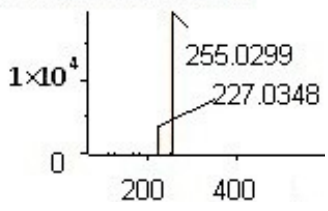

M2

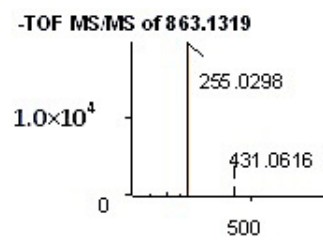

M3

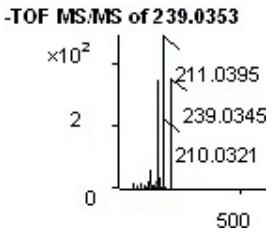

M4

Figure 5. Metabolite chromatogram of purpurin.

Table 3. Information on the metabolites of alizarin.

\begin{tabular}{lllllll}
\hline Peak ID & Formula & $m / z$ & ppm & RT (min) & Peak Area & \% Score \\
\hline M1 & $\mathrm{C}_{20} \mathrm{H}_{16} \mathrm{O}_{10}$ & 415.0670 & 0.3 & 17.16 & $1.19 \times 10^{6}$ & 94.5 \\
M2 & $\mathrm{C}_{14} \mathrm{H}_{8} \mathrm{O}_{7} \mathrm{~S}$ & 318.9917 & 0.4 & 17.85 & $8.44 \times 10^{4}$ & 95.0 \\
M3 & $\mathrm{C}_{20} \mathrm{H}_{16} \mathrm{O}_{10}$ & 415.0672 & 0.2 & 18.27 & $1.52 \times 10^{6}$ & 96.9 \\
M4 & $\mathrm{C}_{14} \mathrm{H}_{8} \mathrm{O}_{7} \mathrm{~S}$ & 318.9917 & 0.3 & 20.58 & $1.89 \times 10^{6}$ & 96.9 \\
\hline
\end{tabular}

Table 4. Information on the metabolites of purpurin.

\begin{tabular}{lllllll}
\hline Peak ID & Formula & $m / z$ & ppm & RT (min) & Peak Area & \% Score \\
\hline M1 & $\mathrm{C}_{20} \mathrm{H}_{16} \mathrm{O}_{11}$ & 431.0611 & 0.6 & 19.43 & $3.20 \times 10^{5}$ & 95.6 \\
M2 & $\mathrm{C}_{20} \mathrm{H}_{16} \mathrm{O}_{11}$ & 431.0613 & 1.2 & 20.09 & $2.19 \times 10^{6}$ & 96.9 \\
M3 & $\mathrm{Unknown}$ & 863.1319 & 0.0 & 20.09 & $9.60 \times 10^{5}$ & 60.8 \\
M4 & $\mathrm{C}_{14} \mathrm{H}_{8} \mathrm{O}_{4}$ & 239.0346 & 1.2 & 30.60 & $2.35 \times 10^{5}$ & 88.3 \\
M & $\mathrm{C}_{14} \mathrm{H}_{8} \mathrm{O}_{5}$ & 255.0301 & 0.1 & 20.09 & $2.04 \times 10^{5}$ & 91.0 \\
\hline
\end{tabular}




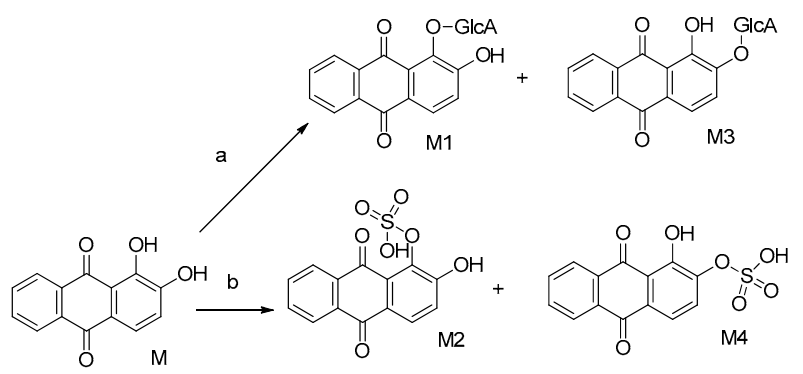

Figure 6. Metabolic pathways of alizarin.

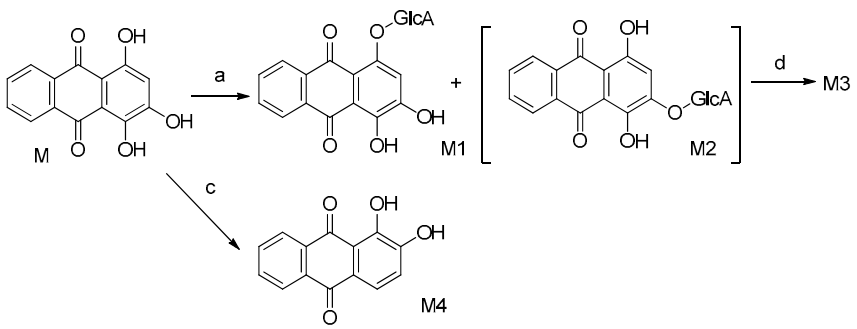

Figure 7. Metabolic pathways of purpurin. Metabolic pathways: (a) glucuronidation; (b) sulfation; (c,d) unknown.

Table 5. Chemical structures of some of the chemical constituents. Anthraquinone structure $\beta$-D-glucopyranosyl (Glc) Glucuronic acid (GlcA).<smiles>[R]c1ccc2c(c1)C(=O)c1c([R4])c([R3])c([R2])c([R])c1C2=O</smiles>

Anthraquinone structure

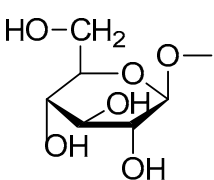

$\beta$-D-glucopyranosyl (Glc)<smiles>COC1OC(C(=O)O)C(O)C(O)C1O</smiles>

Glucuronic acid (GlcA)

\begin{tabular}{|c|c|c|c|c|c|c|c|}
\hline \multirow{2}{*}{ No. } & \multirow{2}{*}{ Compound } & \multirow{2}{*}{ Chemical Formula } & \multicolumn{5}{|c|}{ Substituent Position } \\
\hline & & & $\mathbf{R}_{1}$ & $\mathbf{R}_{2}$ & $\mathbf{R}_{3}$ & $\mathbf{R}_{4}$ & $\mathbf{R}_{6}$ \\
\hline 1 & Alizarin-1-O- $\beta$-glucuronide & $\mathrm{C}_{20} \mathrm{H}_{16} \mathrm{O}_{10}$ & GlcA & $\mathrm{OH}$ & $\mathrm{H}$ & $\mathrm{H}$ & $\mathrm{H}$ \\
\hline 2 & Alizarin-1-O-sulfation & $\mathrm{C}_{14} \mathrm{H}_{7} \mathrm{O}_{4} \mathrm{SO}_{3} \mathrm{H}$ & $\mathrm{OSO}_{3} \mathrm{H}$ & $\mathrm{OH}$ & $\mathrm{H}$ & $\mathrm{H}$ & $\mathrm{H}$ \\
\hline 3 & Alizarin-2-O- $\beta$-glucuronide & $\mathrm{C}_{20} \mathrm{H}_{16} \mathrm{O}_{10}$ & $\mathrm{OH}$ & GlcA & $\mathrm{H}$ & $\mathrm{H}$ & $\mathrm{H}$ \\
\hline 4 & $\begin{array}{l}\text { Purpurin-1-O- } \beta \text {-glucuronide } \\
\text { 2-Methyl-1,3,6-hydroxy-9,10- }\end{array}$ & $\mathrm{C}_{20} \mathrm{H}_{16} \mathrm{O}_{11}$ & GlcA & $\mathrm{H}$ & $\mathrm{OH}$ & $\mathrm{OH}$ & $\mathrm{H}$ \\
\hline 5 & $\begin{array}{l}\text { anthraquinone } \\
3-O-\beta \text {-D-glucopyranoside }\end{array}$ & $\mathrm{C}_{21} \mathrm{H}_{22} \mathrm{O}_{9}$ & $\mathrm{OH}$ & $\mathrm{CH} 3$ & Glc & $\mathrm{H}$ & $\mathrm{OH}$ \\
\hline 6 & Purpurin-3-O- $\beta$-glucuronide & $\mathrm{C}_{2} \mathrm{OH}_{16} \mathrm{O}_{11}$ & $\mathrm{OH}$ & $\mathrm{H}$ & GlcA & $\mathrm{OH}$ & $\mathrm{H}$ \\
\hline 7 & Alizarin-2-O-sulfation & $\mathrm{C}_{14} \mathrm{H}_{7} \mathrm{O}_{4} \mathrm{SO}_{3} \mathrm{H}$ & $\mathrm{OH}$ & $\mathrm{OSO}_{3} \mathrm{H}$ & $\mathrm{H}$ & $\mathrm{H}$ & $\mathrm{H}$ \\
\hline 8 & Pseudopurpurin & $\mathrm{C}_{15} \mathrm{H}_{8} \mathrm{O}_{7}$ & $\mathrm{OH}$ & $\mathrm{OH}$ & $\mathrm{COOH}$ & $\mathrm{OH}$ & $\mathrm{H}$ \\
\hline 9 & Munjistin & $\mathrm{C}_{15} \mathrm{H}_{8} \mathrm{O}_{6}$ & $\mathrm{OH}$ & $\mathrm{COOH}$ & $\mathrm{OH}$ & $\mathrm{H}$ & $\mathrm{H}$ \\
\hline 10 & Nordamnacanthal & $\mathrm{C}_{15} \mathrm{H}_{8} \mathrm{O}_{5}$ & $\mathrm{H}$ & $\mathrm{COOH}$ & $\mathrm{H}$ & $\mathrm{OH}$ & $\mathrm{H}$ \\
\hline 11 & Alizarin-2-O-Glc & $\mathrm{C}_{20} \mathrm{H}_{18} \mathrm{O}_{9}$ & $\mathrm{OH}$ & Glc & $\mathrm{H}$ & $\mathrm{H}$ & $\mathrm{H}$ \\
\hline 12 & 6-Hydroxyrubiadin & $\mathrm{C}_{15} \mathrm{H}_{10} \mathrm{O}_{4}$ & $\mathrm{OH}$ & $\mathrm{CH}_{3}$ & $\mathrm{OH}$ & $\mathrm{H}$ & $\mathrm{H}$ \\
\hline 13 & Alizarin & $\mathrm{C}_{14} \mathrm{H}_{8} \mathrm{O}_{4}$ & $\mathrm{OH}$ & $\mathrm{OH}$ & $\mathrm{H}$ & $\mathrm{H}$ & $\mathrm{H}$ \\
\hline 14 & Purpurin & $\mathrm{C}_{14} \mathrm{H}_{8} \mathrm{O}_{5}$ & $\mathrm{OH}$ & $\mathrm{H}$ & $\mathrm{OH}$ & $\mathrm{OH}$ & $\mathrm{H}$ \\
\hline 15 & Rubiadin & $\mathrm{C}_{15} \mathrm{H}_{10} \mathrm{O}_{4}$ & $\mathrm{OH}$ & $\mathrm{CH}_{3}$ & $\mathrm{OH}$ & $\mathrm{H}$ & $\mathrm{H}$ \\
\hline
\end{tabular}

\subsection{Detection of the Chemical Constituents in Rat Urine}

It could be observed from Table 6 that eight compounds were detected in rat urine. Among them, the compounds 1, 2, 3, and 8 were regarded as metabolites. In comparison, the other compounds were 
regarded as prototypes. However, most of the chemical constituents were not identified. The TIC was shown in Figure 8.

Table 6. Compounds identified in rat urine after oral administration of Rubia cordifolia L. extract.

\begin{tabular}{llllll}
\hline NO. & $\begin{array}{l}\text { RT } \\
(\mathbf{m i n})\end{array}$ & Mass Found & $\begin{array}{l}\text { Error } \\
(\mathbf{p p m})\end{array}$ & $\mathbf{M S}^{\mathbf{2}}$ Ions & Identification \\
\hline $\mathbf{1}$ & 22.24 & 349.0031 & 0.2 & $269,254,226$ & Sulfation of 6-Hydroxyrubiadin \\
$\mathbf{2}$ & 28.89 & 254.0471 & 0.3 & 226,183 & \\
$\mathbf{3}$ & 28.96 & 270.0505 & 0.1 & $255,242,227,196$ & 6-Hydroxyrubiadin \\
$\mathbf{4}$ & 29.53 & 269.0461 & 0.5 & $254,241,223,195$ & Alizarin \\
$\mathbf{5}$ & 30.12 & 239.0350 & 0.6 & $211,195,167,155$ & Purpurin \\
$\mathbf{6}$ & 30.9 & 255.0304 & 0 & $227,183,171,143,129,101$ & Rubiadin \\
$\mathbf{7}$ & 34.32 & 253.145 & 0.5 & $225,209,195$ & \\
$\mathbf{8}$ & 34.37 & 269.0469 & 0 & $241,225,197,182$ & \\
\hline
\end{tabular}
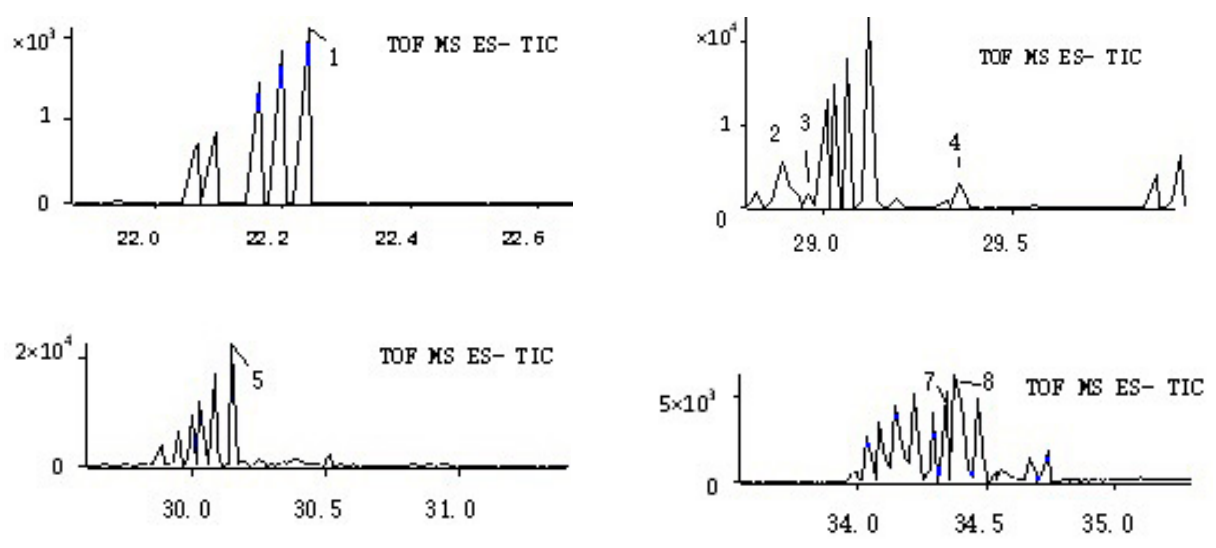

Figure 8. TIC of the rat urine sample.

The parent ion of Compound 1 at a $m / z$ of 349.0031 was 80 Da more than the precursor ion of compound 4 (6-Hydroxyrubiadin). It was regarded as the sulfation product of 6-Hydroxyrubiadin, based on the $\mathrm{MS}^{2}$ spectra (Figure 2). The 6-hydroxyrubiadin was not detected in the rat plasma but it was found in the urine, suggesting that it may not be a bioactive constituent.

\section{Materials and Methods}

\subsection{Chemcials, Reagents, and Meterials}

Rubia cordifolia L. were purchased from Guangdong Medicinal Materials and Yin Pian Company (Guangzhou, China), and were further identified by Professor Ruo-Ting Zhan (Guangzhou University of Traditional Chinese Medicine, Guangzhou, China). The reference standards of alizarin, purpurin, and physcion (purity of $>98 \%$ ) were provided by the China Institute of Pharmaceutical and Miological products, while the 6-pydroxyrubiadin and rubiadin (purity of $>98 \%$ ) were obtained from BioBioPha. HPLC-grade methanol, acetonitrile, and formic acid were purchased from Merck (Merck, Darmstadt, Germany). Purified water was prepared from a Milli-Q system (Millipore Billerica, MA, USA).

\subsection{Instrument and Analytical Conditions}

Chromatographic separation was performed by a Venusil XBP (L) C18 column $(4.6 \times 250 \mathrm{~mm}$, $5 \mu \mathrm{m}$; Agela) at $30{ }^{\circ} \mathrm{C}$. Several mobile phase systems, including methanol-water, acetonitrile-water, acetic acid $(0.1 \%$ and $0.05 \%)$, and formic acid $(0.1 \%$ and $0.05 \%)$ were tested to identify the optimal mobile phase. Ultimately, a mobile phase of acetonitrile (A) and $0.05 \%$ formic acid-water (B) was selected. The gradient program was as follows: $0-10 \mathrm{~min}$ at $10-25 \% \mathrm{~A} ; 10-25 \mathrm{~min}$ at $25-50 \% \mathrm{~A}$; 
$25-35 \mathrm{~min}$ at $50-75 \% \mathrm{~A} ; 35-45 \mathrm{~min}$ at $75 \% \mathrm{~A} ; 45-55 \mathrm{~min}$ at $75-100 \% \mathrm{~A}$; and $55-60 \mathrm{~min}$ at $100 \% \mathrm{~A}$. The mobile phase rate was $0.8 \mathrm{~mL} / \mathrm{min}$ and each injection volume was set at $10 \mu \mathrm{L}$.

The MS data were acquired on an AB SCIEX Triple TOF 5600 (AB sciex Pte. Ltd., Singapore). The Mass spectrometric parameters were as follows: interface of negative electrospray ionization (ESI); gas 1 and 2 being nitrogen $55 \mathrm{psi}$; curtain gas being nitrogen $40 \mathrm{psi}$; source temperature of $400{ }^{\circ} \mathrm{C}$; ion spray voltage of $5500 \mathrm{~V}$; de-clustering potential of $100 \mathrm{~V}$ and collision energy of $45 \mathrm{eV}$. The Peakview (Version 2.0, AB SCIEX) and MetabolitePilot ${ }^{\mathrm{TM}}$ (Version 1.5, AB SCIEX) were employed for the analyses.

\subsection{Animals, Dosage, and Biological Sample Collection}

Eighteen male Sprague-Dawley rats (weight of 180-220 g) were provided by the Experimental Animal Center of the Guangzhou University of Chinese Medicine and randomly divided into three groups (Group I, Group II, and Group III) of six rats each. These animals were housed in a breeding room at a controlled temperature $\left(20-24{ }^{\circ} \mathrm{C}\right)$ and humidity $(40 \%-60 \%)$ in a $12 \mathrm{~h}$ light/dark cycle with free access to food and water for three days. All rats were fasted for $12 \mathrm{~h}$ with free access to water prior to the experiment.

Rubia cordifolia $\mathrm{L}$. was heating by being extracted with $70 \%$ ethanol for $1 \mathrm{~h}$ and then filtered. The moisture in the filtrate was evaporated and the residue was dissolved in methanol to a concentration equivalent to $1 \mathrm{mg} / \mathrm{mL}$ of the Rubia cordifolia $\mathrm{L}$. for analysis.

Rubia cordifolia L. was immersed in $70 \%$ ethanol $(1: 8, w / v)$ and extracted three times $(1 \mathrm{~h}$ each time). The extracted solutions were combined and concentrated under a reduced pressure to a density of $1 \mathrm{~g} / \mathrm{mL}$ for oral administration.

Alizarin solution $(0.63 \mathrm{mg} / \mathrm{mL})$ and purpurin solution $(3.25 \mathrm{mg} / \mathrm{mL})$ were each prepared with $0.5 \%$ aqueous CMCC-Na for oral administration.

The Rubia cordifolia L. solution $(1 \mathrm{~g} / \mathrm{mL})$, the alizarin solution $(0.63 \mathrm{mg} / \mathrm{mL})$, and the purpurin solution $(3.25 \mathrm{mg} / \mathrm{mL})$ were orally administered to group I $(10 \mathrm{~g} / \mathrm{kg}$ body weight), group II $(6.3 \mathrm{mg} / \mathrm{kg}$ body weight), and group III ( $32.5 \mathrm{mg} / \mathrm{kg}$ body weight), respectively. Blank blood samples and medicated blood samples were collected from the suborbital vein before administration and $2 \mathrm{~h}$ after administration, respectively. Following this, these samples were and then immediately centrifuged for 5 min at $14,000 \mathrm{rpm}$ at $4{ }^{\circ} \mathrm{C}$.

All urine samples from group I were collected for $12 \mathrm{~h}$ post-dosing and combined into one sample for the purpose of eliminating the individual variability.

\subsection{Biological Sample Preparation}

The supernatants of the two types of blood samples from the same group were mixed into a single sample to eliminate individual interference. A total of $200 \mu \mathrm{L}$ aliquots of mixed plasma samples were precipitated with $800 \mu \mathrm{L}$ methanol and vortexed for $5 \mathrm{~min}$. The sample was centrifuged at 14,000 rpm for $5 \mathrm{~min}$, and beforehand the supernatant was separated and dried under a stream of nitrogen gas at $30{ }^{\circ} \mathrm{C}$. The residue was dissolved in $200 \mu \mathrm{L}$ of methanol, before $10 \mu \mathrm{L}$ of this mixture was injected into the UPLC/Q-TOF/ MS for analysis.

The mixed urine sample was homogenized with methanol at a ratio of 1:4, before being vortexed and centrifuged at 14,000 rpm for $5 \mathrm{~min}$. Following this, the supernatant was removed and evaporated to dryness. The residue was dissolved in $200 \mu \mathrm{L}$ of methanol for UPLC/Q-TOF MS analysis.

\section{Conclusions}

In this study, a UPLC/Q-TOF-MS method was established for studying the metabolism of Rubia cordifolia L. Eventually, nine prototype components and six metabolites including alizarin-1-O- $\beta$-glucuronide, alizarin-2-O- $\beta$-glucuronide, alizarin-1-O-sulfation, alizarin-2-O-sulfation, purpurin-1-O- $\beta$-glucuronide, and purpurin-3-O- $\beta$-glucuronide were identified in the plasma. Also, this indicates that the metabolic pathway of alizarin involves glucuronidation and sulfation, with the 
purpurins having undergone glucuronidation. Thus, Rubia cordifolia L. possibly express its effects through their metabolites. Additionally, it is interesting that purpurin can transform into alizarin in rat body. Research has made it clear that alizarin and purpurin both can induce gene mutations that contribute to cases of nephrotoxicity $[25,26]$. Thus, it is hypothesized that alizarin, instead of purpurin, is associated with the noxious effects to kidney. The analysis of the changes in purpurin content in the body may be the best way to understand the metabolic pathways of purpurin. Furthermore, four prototype components were identified in urine. The 6-pydroxyrubiadin was only detected in the urine, suggesting that it may not be the active substance of Rubia cordifolia L. However, further studies based on the nuclear magnetic resonance technology (NMR) are needed to identify the unidentified compounds. This experiment might provide a basis for further pharmacological and pharmacokinetic research on Rubia cordifolia L.

Acknowledgments: This work was supported by the Chinese Medicinal Materials Production and Construction Projects of the Ministry of Industry and Information Technology of China ((2015) no. 282); the Collaborative Innovation Center Research Team Construction Project in Guangdong Province the Innovation Research Team of Traditional Chinese Medicine Resources (A1-AFD01514A04); The Ministry of Education of Guangdong Province, by the combination of production and research projects (2012B091100183) and The Science and Technology Planning Project, Guangdong Province of China (2016ZC0098) and High level university project, Guangzhou University of Chinese Medicine (Guang Zhong Yi Yan (2017) no. 10) and Soft science research project of Guangdong Intellectual Property Office (GDIP2016-G3) and The Science and Technology Planning Project, Guangdong Province of China (2015A070703015).

Author Contributions: Z.Z., Y.Z., S.L., H.P. and Y.Y. designed the research; Z.Z. and P.Y. performed the research; Z.Z., R.Z. and P.Y. analyzed the data; Z.Z. and P.Y. wrote the paper.

Conflicts of Interest: The authors declare no conflict of interest.

\section{References}

1. Zhao, S.M.; Wang, Z.; Zeng, G.Z.; Song, W.W.; Chen, X.Q.; Li, X.N. New cytotoxic Naphthohydroquinone dimmers from Rubia altata. Org. Lett. 2014, 16, 5576-5577. [CrossRef] [PubMed]

2. Talapatra, S.K.; Sarkar, A.C.; Talapatra, B. Two pentacyclic triterpenes from Rubia cordifolia. Phytochemistry 1981, 20, 1923-1924. [CrossRef]

3. Arisawa, M.; Ueno, H.; Nimura, M.; Hayashi, T.; Morita, N. Rubiatriol a New Triterpenoid from the Chinese Drug "Qian Cao Gen," Rubia cordifolia. J. Nat. Prod. 1986, 49, 1114-1116. [CrossRef]

4. Inouye, H.; Takeda, Y.; Nishimura, H.; Kanomi, A.; Okuda, T.; Puff, C. Chemotaxonomic studies of rubiaceous plants containing iridoid Glycosides. Phytochemistry 1998, 27, 2591-2598. [CrossRef]

5. Bianco, A.; Guiso, M.; Iavarone, C.; Passacantilli, P.; Trogolo, C. Iridoids. XXV. New iridoid glucosides from Rubiaceae. Gaz. Chim. Ital. 1978, 108, 13-18.

6. Wang, X.J.; Zhang, A.H.; Sun, H.; Han, Y.; Yan, G.L. Guidelines for the use and interpretation of assays for monitoring autophagy (3rd edition). Autophagy 2016, 12, 1-222.

7. Singh, N.P.; Gupta, A.P.; Sinha, A.K.; Ahuja, P.S. High-performance thin layer chromatographymethod for quantitative determination of four major anthraquinone derivatives in Rheum emodi. J. Chromatogr. A 2005, 1077, 202-206. [CrossRef] [PubMed]

8. Nakanishi, F.; Nagasawa, Y.; Kabaya, Y.; Sekimoto, H.; Shimomura, K. Characterization of lucidin formation in Rubia tinctorum L. Plant Physiol. Biochem. 2005, 43, 921-928. [CrossRef] [PubMed]

9. Agarwal, S.K.; Singh, S.S.; Verma, S. Antifungal activity of anthraquinone derivatives from Rheum emodi. J. Ethnopharmacol. 2008, 72, 43-46. [CrossRef]

10. Yen, G.C.; Duch, P.D.; Chuang, D.Y. Antioxidant activity of anthraquinones and anthrone. Food Chem. 2000, 70, 437-441. [CrossRef]

11. Fenig, E.; Nordenberg, J.; Beery, E. Combined effect of aloe-emodin and chemotherapeutic agents on the proliferation of an adherent variant cell line of Merkel cell carcinoma. Oncol. Rep. 2004, 11, $213-217$. [CrossRef] [PubMed]

12. Ifesan, B.O.; Hamtasin, C.; Mahabusarakam, W. Assessment of antistaphylococcal activity of partially purified fractions and pure compounds from Eleutherine americana. J. Food Prot. 2009, 72, 354-359. [CrossRef] [PubMed] 
13. Zengin, G.; Degirmenci, N.S.; Alpsoy, L.; Aktumsek, A. Evaluation of antioxidant, enzyme inhibition, and cytotoxicc activity of three anthraquinones (alizarin, purpurin, and quinizarin). Hum. Exp. Toxicol. 2016, 35, 544-553. [CrossRef] [PubMed]

14. Lee, Y.M.; Auh, A.S.; Lee, D.W.; Kim, J.Y.; Jung, H.J.; Lee, S.H.; Kim, E.C. Involvement of Nrf2-Mediated Upregulation of Heme Oxygenase-1 in Mollugin-Induced Growth Inhibition and Apoptosis in Human Oral Cancer Cells. BioMed Res. Int. 2013, 36, 399-406. [CrossRef] [PubMed]

15. Wu, C.C.; Li, X.B.; Han, T.S.; Li, P.; Wang, Z.; Ge, C.R.; Gao, S.Z. Dietary Pseudopurpurin Effects on Bone Mineral Density and Bone Geometry Architecture in Rats. Int. J. Mol. Sci. 2012, 13, 3431-3443. [CrossRef] [PubMed]

16. Guntupalli, M.; Mohana, R. Hepatoprotective effects of rubiadin, a major constituent of Rubia cordifolia Linn. J. Ethnopharmacol. 2006, 103, 484-490.

17. Chen, L.L.; Qi, J.; Chang, Y.X.; Zhu, D.N.; Yu, B.Y. Identication and determination of the major constituents in Traditional Chinese Medicinal formula Danggui-Shaoyao-San by HPLC-DAD-ESI-MS/MS. J. Pharm. Biomed. Anal. 2009, 50, 127-137. [CrossRef] [PubMed]

18. Bao, B.H.; Kang, A.; Zhao, Y.; Shen, Q.; Li, J.S.; Di, L.Q.; LI, J.X. A selective HPLC—MS/MS method for quantification of SND-117 in rat plasma and its application to a pharmacokinetic study. J. Chromatogr. B 2017, 1052, 60-65. [CrossRef] [PubMed]

19. Romanski, M.; Kasprzyk, A.; Tezyk, A.; Widerowska, A.; Zaba, C.; Glowka, F. Determination of prodrug treosulfan and its biologically activemonoepoxide in rat plasma, liver, lungs, kidneys, muscle, and brain by HPLC-ESI-MS/MS method. J. Pharm. Biomed. Anal. 2017, 140, 122-129. [CrossRef] [PubMed]

20. Huang, J.T.; Cheng, Y.Y.; Lin, L.C.; Tsai, T.H. Structural Pharmacokinetics of Polymethoxylated Flavones in Rat Plasma Using HPLC-MS/MS. J. Agric. Food Chem. 2017, 65, 2406-2413. [CrossRef] [PubMed]

21. Zhong, Y.; Sun, M.; Xing, J.; Corke, H. Antioxidant phenolic constituents in roots of Rheum officinate and Rubia cordifolia: Structure-radical scavenging activity relationships. J. Agric. Food Chem. 2004, 52, 7884-7890.

22. Boldizsar, I.; Szucs, Z.; Fuzfai, Z.; Perl, I.M. Identification and quantification of the constituents of madder root by gas chromatography and high-performance liquid chromatography. J. Chromatogr. A 2006, 1133, 259-274. [CrossRef] [PubMed]

23. Liu, W.; Zheng, Z.; Liu, X. Sensitive and bobust UPLC-MS/MS method to determine the gender-dependent pharmacokinetics in rats of emodin and its gluccuronide. J. Pharm. Biomed. Anal. 2011, 54, 1157-1162. [CrossRef] [PubMed]

24. Tian, J.; Chen, X.; Bai, X.L. Analysis of emodin and its metabolites based on hohow fiber liquid phase microextraction. Chin. J. Chromatogr. 2012, 30, 507-514. [CrossRef]

25. Westendorf, J.; Marquardt, H.; Poginsky, B. Genotoxicity of naturally occurring hydroxy-anthraquiniones. Mutat. Res. 1900, 240, 1-12. [CrossRef]

26. Walker, N.I.; Bennett, R.E.; Axelsen, R.A. Melanosis coil A consequence of anthraquinone induced apoptosis of colonic epithelial cell. Am. J. Pathol. 1998, 131, 464-465.

Sample Availability: Samples of the Rubia cordifolia L. extract, rat plasma and rat urineare available from the authors. All reference standards are available online.

(C) 2017 by the authors. Licensee MDPI, Basel, Switzerland. This article is an open access article distributed under the terms and conditions of the Creative Commons Attribution (CC BY) license (http:/ / creativecommons.org/licenses/by/4.0/). 